Case report

\title{
Impact of HIV vaccination on laboratory diagnosis: case reports
}

Vongsheree Suthon*1, Rojanawiwat Archawin ${ }^{1}$, Chardbanchachai Chanchai ${ }^{2}$, Lerwitworapong John², Kongpromsook Wichuda ${ }^{2}$, Paungtubtim Wiroj ${ }^{1}$, Thaisri Hansa ${ }^{1}$, Sawanpanyalert Pathom ${ }^{1}$, Sri-ngam Pongnuwat ${ }^{1}$, Pithak Silaporn ${ }^{1}$ and Inunchot Wimala ${ }^{1}$

Address: ${ }^{1}$ National Institute of Health, Department of Medical Science, Ministry of Public Health, Thailand and ${ }^{2}$ Central Correction Hospital, Department of Corrections, Ministry of Interior, Thailand

E-mail: Vongsheree Suthon* - suthon@dmsc.moph.go.th; Rojanawiwat Archawin - aechawim191@yohoo.com;

Chardbanchachai Chanchai - chadbuncha@hotmail.com; Lerwitworapong John - john@samarts.com;

KongpromsookWichuda - kvichuda@yahoo.com; Paungtubtim Wiroj - wirojptt@yahoo.com; Thaisri Hansa - hansat@dmsc.moph.go.th; Sawanpanyalert Pathom - pathoms@loxinfo.co.th; Sri-ngam Pongnuwat - p_nuwat@hotmail.com; Pithak Silaporn - kungfumail@yahoo.com; Inunchot Wimala - wimalain@yahoo.com

*Corresponding author

Published: 10 September 2002

BMC Infectious Diseases 2002, 2:19
Received: 10 June 2002

Accepted: 10 September 2002

This article is available from: http://www.biomedcentral.com/147/-2334/2/19

(C) 2002 Suthon et al; licensee BioMed Central Ltd. This article is published in Open Access: verbatim copying and redistribution of this article are permitted in all media for any non-commercial purpose, provided this notice is preserved along with the article's original URL.

\begin{abstract}
Background: It has not been clearly demonstrated whether HIV vaccination can complicate routine HIV testing. In this report, we describe the laboratory data of two prisoners who received rgp/20 vaccine in a phase III trial underway in Thailand. These data indicate that previous vaccination may complicate the interpretation of screening HIV diagnostic tests.
\end{abstract}

Case presentation: The participants were identified from a cohort study on "Health factors related to HIV-I and other viral infections among incarcerated people" that was approved by The Ethical Committee for Research in Human Subjects, Ministry of Public Health, Thailand. HIV diagnosis was definitively established with serial specimens using multi-screening tests, Western blot and diagnostic PCR.

Anti-HIV screening tests consistently exhibited either weakly reactive or inconclusive results. The band patterns of the Western blot analysis corresponded to those found in individuals who received the rgPl20 vaccination. Definite results were established using diagnostic PCR, which exhibited consistently negative results with follow-up specimens. Such problems in HIV testing are not easily resolved in the routine clinical setting in Thailand.

Conclusions: These data demonstrate that HIV-I vaccination interferes with routine diagnostic tests. Similar cases will not be uncommon in Thailand, where 2,545 people have already participated in a phase III trial. 


\section{Background}

At present, there is only one protective human immunodeficiency virus type 1 (HIV-1) vaccine undergoing phase III trials.[1,2] In 1998, the phase I/II trial was conducted among 33 injecting drug users in Bangkok, Thailand, using rgp 120 derived from HIV 1 subtype $B(\mathrm{MN})$. The preliminary data of the phase I/II trials demonstrated acceptable safety and immunogenicity, with some breakthrough infections. Then, a randomized (ratio1: 1), double-blind, placebo-controlled phase III trial, using a bivalent rgp 120 vaccine derived from subtype B (MN) and subtype E (244), was initiated in March 1999, in Bangkok, Thailand, with 2,545 injecting drug users. The final result on the efficacy of this vaccine may be expected in late 2003. Indeed, almost $100 \%$ of vaccinated individual seroconverted following immunization and developed a high antibody titer.[3,4] The development of antibody following vaccination would be predicted to interfere with anti-HIV screening tests but there are few reports describing such complications.[5-7] In the trials, vaccinated individuals are distinguished from HIV infected cases by nucleic acid tests such as PCR. [4,8,9] However, it is questionable whether or not the technique of PCR can be routinely implemented in the trial sites. [9] In this report, we present data derived from two vaccinated individuals whose vaccination history was not known before inconclusive anti-HIV test results were observed. The confounding effects of vaccination upon subsequent HIV testing are discussed and recommendations suggested.

\section{Case presentation Setting}

The two cases reported were male prisoners selected from among 689 participants in a study on health factors related to HIV-1 and other viral infections among incarcerated people. The study was reviewed and approved in 2001 by The Ethical Review Committee for Research in Human Subjects, Ministry of Public Health, Thailand. Participants received a thorough explanation of the study, including the risks and benefits, and gave signed informed consent prior to entry into the study. Patients were visited monthly during the 6-month period of follow-up. At each visit, the participants were interviewed regarding their risk behaviors, received pre-test or post-test counseling and gave samples for laboratory tests.

Table I: Laboratory data of KP 548 and KP 667

\begin{tabular}{|c|c|c|c|c|c|c|c|c|}
\hline & KP 548 & & & & KP 66 & & & \\
\hline Bleeding time (day) ${ }^{*}$ & 0 & 14 & 28 & 60 & 0 & 14 & 28 & 60 \\
\hline EIAI (index) ${ }^{* *}$ & 2.44 & 1.72 & 1.92 & 1.14 & 0.95 & 0.99 & 1.54 & 0.93 \\
\hline EIA2 (index) ${ }^{* * * * *}$ & 1.31 & 1.03 & 0.91 & 0.65 & 0.09 & 0.09 & 0.12 & 0.11 \\
\hline GPA & NR & NR & NR & NR & NR & NR & NR & NR \\
\hline \multicolumn{9}{|l|}{ WB pattern } \\
\hline$g p 160$ & $1+$ & $1+$ & $1+$ & $+/-$ & - & - & - & - \\
\hline gP 120 & $4+$ & $3+$ & $3+$ & $3+$ & $+/-$ & $1+$ & $3+$ & $2+$ \\
\hline P5I & $+/-$ & - & $+/-$ & $+/-$ & - & - & - & - \\
\hline gp 4l & $4+$ & $3+$ & $3+$ & $2+$ & - & - & - & - \\
\hline P3I & - & - & - & - & $2+$ & $2+$ & $2+$ & $2+$ \\
\hline Interpretation & Pos & Pos & Pos & Pos & ID & ID & ID & ID \\
\hline \multicolumn{9}{|l|}{ PCR } \\
\hline DNA-PCR & Neg & Neg & Neg & Neg & Neg & Neg & Neg & Neg \\
\hline RT-PCR & Neg & Neg & Neg & Neg & Neg & Neg & Neg & Neg \\
\hline
\end{tabular}

day after first visit; ${ }^{* *}$ EIA , Vironostika, Uni-Form II Ag/Ab; *** EIA , Abbott HIVI/2 gr O EIA; GPA, Gel particle agglutination; WB, Western blot; Pos, Positive result; Neg, Negative result; NR, non-reactive; index, OD/Cutoff value; ID, Indeterminate result; I+ to 4+, relative intensities of bands in WB as compared to those of weakly reactive control; Interpretation criteria for positive WB was the presence of 2 envelopes +/- gag +/- pol, as recommended by the manufacturer. 


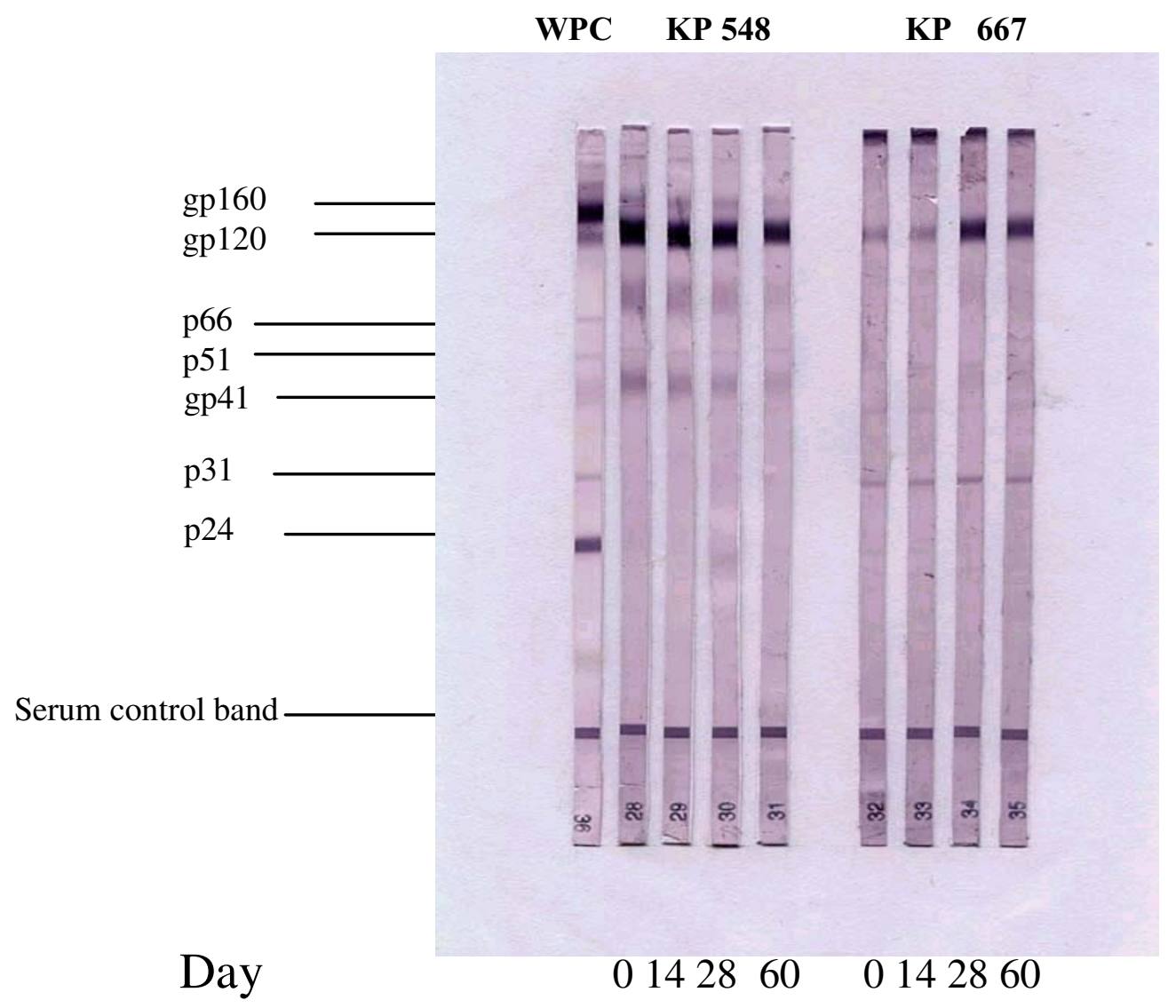

Figure I

Western Blot results of KP 548 and KP667 *Day after first visit. WPC: weak positive control

\section{Laboratory tests}

HIV diagnosis was established by a combination of screening tests as recommended by the WHO[10] and Ministry of Public Health, Thailand.[11] HIV-1 antibody testing was performed with a two enzyme immunoassay (EIA) using Uni-Form II Ag/Ab (Organon Technika) and HIV1/2 gr. O EIA (Abbott laboratories) together with a gel particle agglutination test (GPA, Fugirebio Inc.). Positive anti-HIV results were reported after concordant reactive results were observed. In the case of discordant results from these screening tests, the specimens underwent Western blot analysis (HIV blot 2.2, Genelabs diagnostic) and HIV-1 RNA and DNA were detected by in-house PCR as described in a previous report.[12]

\section{Results}

I. Characteristics of the cases

KP 548 and KP 667 were heroin users (by injection) since 1991 (KP 548) and 1994 (KP 667). They had shared needles before and during incarceration. In addition, KP 667 shared needles with two HIV-infected prisoners. However, both KP 548 and KP 667 were anti-HIV negative in the latest tests undertaken in 2001.

\section{Laboratory data}

The results of screening tests on KP 548 and KP 667 were consistently discordant at the first visit and 2, 8 and 14 weeks later. All specimens were analyzed by Western blot that demonstrated unique high intensities of gp120 but 
minor or undetectable gp160. Such Western blot banding patterns were not found in any HIV-1 infected cases. After analysis of the serial specimens, the serological test results remained inconclusive and indeterminate Both RT-PCR and DNA PCR for HIV-1 were consistently negative in all the samples. The history of vaccination was elicited at the fourth visit after a 2 -month period of follow-up. Detailed laboratory data is illustrated in Table 1.

\section{Discussion and conclusion}

KP548 and KP667 were two out of 2,545 individuals involved in a phase III trial in Thailand. Their clinical specimens were tested for HIV-1 infection using the same test algorithm used for routine individual diagnostic specimen testing. Their vaccination history was not known since such data was not included in both the questionnaire and the pre-test counseling but was discovered by the laboratory test results and was confirmed by retrospective interviewing of the cases. Thus, a vaccination history should be included in the standard pre-test counseling both for diagnosis and blood safety. Secondly, the vaccine induced antibody response can complicate anti-HIV-1 screening tests. Similar complications were observed among vaccinees in the phase I/II trial. The vaccine had induced antibody that was detectable by EIAs and Western blot. The extent of reactivity of the tests was depended on antigenic determinants of the tests and the vaccines.[6,7] The weakly reactive EIA and discordant screening test results were similar to those of early seroconverters. However, the follow-up testing exhibited stable signals in the EIA and Western blot, while those of early seroconverters should be increasing. Thirdly, the Western blot results were incorrectly reported as anti-HIV positive if the band intensities were not scored. As demonstrated in Figure 1, the intensities of gp120 were significantly higher than the intensities of gp160. Such relative intensities were not observed in any HIV-1 infected cases. Finally, the definite diagnosis was obtained after PCR testing of serial specimens. However, PCR testing is not available or affordable for all laboratories in Thailand, except in the case of a few research settings. Furthermore, such viral genome detection test is prone to contamination as demonstrated in a vaccinee who got repeatedly false positive HIV RTPCR.[9] These two cases demonstrate the potential impact of HIV vaccination on the laboratory diagnosis of HIV in all places where people have access to HIV vaccines. Another complication of HIV vaccine trial is trial-related discrimination that occurred at $5 \%$ of the volunteers. Among these events, $10 \%$ was reported to be linked with HIV testing.[5] The design of efficacy trial of new HIV vaccines should be in parallel with development of novel diagnostic tests that are capable of differentiating between immunization and true HIV infection.

\section{Competing interests}

None declared.

\section{Authors' contributions}

All authors read and approved the final manuscript and contributed equally to the manuscript.

\section{Acknowledgements}

The authors would like to thank all of the staff of the Department of Corrections, Ministry of Interior, Thailand, for their excellent cooperation. The study was supported by the Annual Budget, Thai government. The patients gave their informed consent for the publication of their data as indicated in the ethical approved protocol.

\section{References}

I. Francis DP, Gregory T, McElrath MJ, Belshe RB, Gorse GJ, Migasena S, Kitayaporn D, Pitisuttitham P, Matthews T, Schwartz DH, Berman PW: Advancing AIDSVAX to phase 3. Safety, immunogenicity, and plan for phase 3. AIDS Res Hum Retroviruses 1998, I 4(Suppl 3):S325-S331

2. The HIVIAIDS Collaboration, Thailand: Annual Report for 2000200 I. Part C. HIV transmission among injecting drug users and HIV vaccine efficacy trial 30-35

3. Phanupak P, Teeratakulpixarn S, Sarangbin S, Nookhai S, Ubolyam S, Sirivichayabul S, Leesavan A, Forrest BD, Hanson CV, Li M, Wang CY, et al: International clinical trials of HIV vaccines: I. Phase I trial of an HIV-I synthetic peptide vaccine in Bangkok, Thailand. Asian Pac J Allergy Immunol I 997, I 5( I):41-48

4. Migasena S, Suntharasamai P, Pitisuttitham P, Kitayaporn D, Wasi C, Huang W, Vanichseni S, Koompong C, Kaewkungwal J, Raktham S, et al: AIDSVAX (MN) in Bangkok injecting drug users: a report on safety and immunogenicity, including macrophage-tropic virus neutralization. AIDS Res Hum Retrovirus 2000, I6(7):655$663.41-48$

5. Allen M, Israel H, Rybezyk K, Pugliese MA, Loughran K, Wagner L, Erb $\mathrm{S}$ : Trial-related discrimination in HIV vaccine clinical trials. AIDS RES Hum Retroviruses 200I, 17(8):667-674

6. Evans TG, Keefer MC, Belse RB, Schwartz D, Graham BS, Corry L, Mulligan MJ, Stablein D, and the AIDS Vaccine Evaluation Group: Rates and determinants of positive HIV screening results in uninfected participants in phase I/II trials of candidate HIV-I vaccines. In Abstracts of the 1999 National HIV Prevention Conference; Atlanta; GA Abstract 293September 1999

7. Eastman D, Sheppard HWC, Dondero D, Ivanoft R, Ackers M, McDougal S, Parekh B, La-Ong S, Berman PW: Evaluation of commercial HIV diagnostic assays with sera obtained from volunteers immunized with recombinant gp I 20 based subunit vaccines. In Abstracts of the XIII International AIDS Conference; Durban, South Africa MoPeA2135July 2000

8. Berman PW, Gray AM, Wrin T, Vennari JC, Eastman DJ, Nakamura GR, Francis DP, Gorse G, Schwartz DH: Genetic and immunologic characterization of virus infecting MN-rgp I 20-vaccinated volunteers. I Infect Dis 1997, 1 76:384-397

9. Schwartz DH, Laeyendecker OB, Arango-Jaramillo S, Castillo RC, Reynolds MJ: Extensive evaluation of a seronegative participant in an HIV-I vaccine trial as a result of false-positive PCR. Lancet 1997, 350:256-259

10. WHO: The importance of simple rapid assays in HIV testing. WHOI UNAIDS recommendations. Weekly Epidemiological Report 1998, 73(42):32I-328

II. Ministry of Public Health, Thailand: National guideline for HIV testing. Bangkok 1996

12. Vongsheree S, Ruchusatsawat N, Saguanwongse S, Warachit P: Diagnosis of perinatal HIV-I infection by in-house PCR. Asian Pac J Allergy Immunol 1997, I 5:199-204

\section{Pre-publication history}

The pre-publication history for this paper can be accessed here:

http://www.biomedcentral.com/1471-2334/2/19/prepub 